\title{
Growth Hormone Treatment and Papilledema: A Prospective Pilot Study
}

\author{
(D) Nieves Martín-Begué1, (D) Eduard Mogas², (D) Charlotte Wolley Dod¹, (D) Silvia Alarcón¹, (D) María Clemente2,3,4, \\ (D) Ariadna Campos-Martorell2,3, (D) Ana Fábregas2, (D) Diego Yeste2,3,4 \\ ${ }_{1}^{1}$ Hospital Universitari Vall d'Hebron, Department of Paediatric Ophthalmology, Barcelona, Spain \\ ${ }^{2}$ Hospital Universitari Vall d'Hebron, Department of Paediatric Endocrinology, Barcelona, Spain \\ 3 Universitat Autònoma de Barcelona (UAB), Barcelona, Spain \\ ${ }^{4}$ Centro de Investigación Biomédica en Red: Enfermedades Raras (CIBERER), Madrid, Spain
}

\section{What is already known on this topic?}

Growth hormone $(\mathrm{GH})$ replacement therapy is a risk factor for secondary pseudotumor cerebri. The incidence of this complication can vary depending on different GH indications.

\section{What this study adds?}

Children with intracranial hypertension could be asymptomatic, so the diagnosis should be based on fundus examination and not on patient's symptoms. In our series, at risk patients had GH deficiency and hypothalamic-pituitary anatomic anomalies or genetic or chromosomal diseases. A previous history of pseudotumor cerebri should be investigated.

\section{Abstract}

Objective: To investigate the incidence of pseudotumor cerebri syndrome (PTCS) in children treated with growth hormone (GH) in a paediatric hospital and to identify risk factors for this complication.

Methods: Prospective pilot study of paediatric patients treated with recombinant human GH, prescribed by the Paediatric Endocrinology Department, between February 2013 and September 2017. In all these patients, a fundus examination was performed before starting treatment and 3-4 months later.

Results: Two hundred and eighty-nine patients were included, of whom 244 (84.4\%) had GH deficiency, 36 (12.5\%) had short stature associated with small for gestational age, six (2.1\%) had a mutation in the SHOX gene and three (1.0\%) had Prader-Willi syndrome. Five $(1.7 \%)$ developed papilledema, all were asymptomatic and had GH deficiency due to craniopharyngioma $(\mathrm{n}=1)$, polymalformative syndrome associated with hypothalamic-pituitary axis anomalies $(n=2)$, a non-specified genetic disease with hippocampal inversion $(n=1)$ and one with normal magnetic resonance imaging who had developed a primary PTCS years before.

Conclusion: GH treatment is a cause of PTCS. In our series, at risk patients had GH deficiency and hypothalamic-pituitary anatomic anomalies or genetic or chromosomal diseases. Fundus examination should be systematically screened in all patients in this at-risk group, irrespective of the presence or not of symptoms.

Keywords: Growth hormone treatment, pseudotumor cerebri syndrome, idiopathic intracranial hypertension, papilledema, risk factors

\section{Introduction}

Pseudotumor cerebri syndrome (PTCS) is a condition defined by elevated intracranial pressure (ICP) in the absence of clinical, laboratory or radiologic evidence of infection, vascular abnormality, intracranial space-occupying lesion or hydrocephalus $(1,2)$. It can be primary, or secondary if there are any identifiable risk factors. Primary PTCS most commonly occurs in obese adult women of childbearing age $(12-32 / 100,000)$. However, it is a rare condition in childhood
Address for Correspondence: Nieves Martín-Begué MD, Hospital Universitari Vall d'Hebron, Department of Paediatric Ophthalmology, Barcelona, Spain

Phone: +034934893166 E-mail: nmartin@vhebron.net ORCID: orcid.org/0000-0003-0365-1266
Conflict of interest: None declared Received: 16.01 .2020 Accepted: 16.09 .2020

${ }^{\circ}$ Copyright 2021 by Turkish Pediatric Endocrinology and Diabetes Society

The Journal of Clinical Research in Pediatric Endocrinology published by Galenos Publishing House. 
(0.5-0.9/100,000) with an identifiable risk factor in 53$77 \%$ of paediatric cases $(3,4,5)$. Papilledema is a hallmark in PTCS, which is not a benign disorder; there is a risk of severe and permanent visual loss. Even patients with mild visual loss experience reduction in quality of life (6).

Growth hormone (GH) replacement therapy was first associated with PTCS by The Food and Drug Administration in 1993 (7). Since then, multiple publications have described this association. Reeves and Doyle (8) found that the prevalence in the $\mathrm{GH}$ treated population was approximately 100 times greater than in the general paediatric population. This complication usually occurs in the first weeks after initiating treatment (approximately 2-12 weeks) and the papilledema (optic disc swelling from raised ICP) resolves on stopping treatment $(8,9)$.

Pseudopapilledema is an elevated optic disc with obscured margins that may occur in hyperopic eyes and in the presence of buried optic disc drusen, rather than from raised ICP. Optic disc drusen are acellular deposits located within the optic disc. Sometimes it can be very difficult to differentiate between pseudopapilledema and papilledema, requiring the opinion of a suitably experienced ophthalmologist and complementary tests (10).

The aim of this study was to investigate the incidence of PTCS in children treated with GH in a paediatric hospital and to identify risk factors for this complication. A secondary aim was to identify which children really need fundus examination during $\mathrm{GH}$ treatment in order to detect this complication.

\section{Methods}

A prospective pilot study was conducted in paediatric patients who started GH treatment from February 2013 to September 2017. Inclusion criteria were patients under 16 years of age prescribed GH by the Paediatric Endocrinology Department. Exclusion criteria were: absence of fundus examination prior to or at 3-4 months from starting treatment; severe optic disc atrophy where optic disc swelling would not develop; and cases where GH was prescribed by the Paediatric Nephrology Department. Predisposing pathology for intracranial hypertension was not considered an exclusion criterion, as fundus examinations were conducted before initiating treatment to rule out prior pathology of the optic nerve. The following variables were recorded: previous medical history; anthropometric data; and compliance with treatment.

Fundus was explored prior to and after 3-4 months of starting treatment or at any time when severe constant headache, vomiting or other presenting symptoms suggestive of intracranial hypertension arose. Prior fundus examination identified possible cases of pseudopapilledema and avoided possible confusion between this entity and newly developed papilledema in subsequent fundus follow-up examinations.

Fundus examination was carried out with indirect ophthalmoscopy and retinography was taken in cases of pseudopapilledema to facilitate follow up. In cases when papilledema was detected, GH was stopped and fundus examination was repeated four weeks later. If papilledema persisted, the patient was referred for neurological assessment, lumbar puncture and possible medical treatment with acetazolamide. Once papilledema resolved, if GH treatment was still considered necessary, treatment was re-initiated at a lower dose and progressively increased until the objective dose was achieved, with monthly ophthalmology visits until four months were completed at the target GH dose.

Cerebral magnetic resonance imaging (MRI) of the hypothalamic-pituitary axis was performed in all patients with $\mathrm{GH}$ deficiency, prior to treatment. Initial GH doses were as indicated: $0.028-0.035 \mathrm{mg} / \mathrm{kg} /$ day for patients with $\mathrm{GH}$ deficiency and small for gestational age (SGA), $0.042 \mathrm{mg} / \mathrm{kg} /$ day for those with mutations in the SHOX gene and $1 \mathrm{mg} /$ $\mathrm{m}^{2} /$ day for patients with Prader-Willi syndrome (PWS).

Ethics approval was obtained from the Ethic Review Committee of the Hospital Universitario Vall d'Hebron (approval number: 383). All subjects (or their parents or guardians) gave their written informed consent.

\section{Statistical Analysis}

In this case series, simple descriptive statistics were sufficient to delineate our populations. Variables are expressed as number, mean and percent (\%) or range, as appropriate.

\section{Results}

There were 306 patients to whom GH was prescribed by the Paediatric Endocrinology Department between February 2013 and September 2017. Only 289 patients were enrolled in this study, 17 were excluded because of loss of ophthalmological follow up.

The mean age was nine years (range 1-16) and $53 \%$ of the patients were male. The patients were categorized according to their indication for GH treatment: 244 patients (84.4\%) with GH deficiency; 36 patients (12.5\%) with short stature associated with SGA; six patients $(2 \%)$ with a mutation in the SHOX gene; and three (1\%) with PWS. Patients 
diagnosed with chronic kidney disease were not included in the study as their indication for GH treatment and follow up was made by the Paediatric Nephrology Department.

In the first visit, prior to starting $\mathrm{GH}$ treatment, there were 546 eyes with normal optic discs, 16 eyes with pale optic discs, 11 eyes with pseudopapilledema, two eyes with optic disc and chorioretinal coloboma and one eye with dysplastic optic disc. Pale optic discs and optic disc and chorioretinal coloboma were secondary to the patient background pathology, suprasellar cerebral tumours and CHARGE anomaly respectively. In the follow up visit, five patients had optic disc swelling, suggesting papilledema, despite there being no symptoms of intracranial hypertension. None of the patients who presented with headache, who were visited urgently, presented with papilledema on fundus examination.

Table 1 outlines the characteristics of the five patients with papilledema. All these patients had GH deficiency: three had hypothalamic-pituitary axis abnormalities on brain MRI; two were congenital cases; and one was secondary to a suprasellar tumour. The patient with a suprasellar tumour had a ventriculoperitoneal shunt and was treated with external radiotherapy. The only patient with an isolated GH deficiency with normal MRI, had developed primary PTCS five years before and he was obese. The incidence of obesity in children without PTCS in our population is $10.3 \%$.

The papilledema resolved on discontinuing GH treatment in four patients, whereas in the remaining patient, a lumbar puncture confirmed the diagnosis and was also therapeutic. The opening pressure was $25 \mathrm{~cm} \mathrm{H}_{2} \mathrm{O}$. The glucose was $61 \mathrm{mg} / \mathrm{dL}$ (38-82); protein $20 \mathrm{mg} / \mathrm{dL}(15-45)$ and there were neither leukocytes nor red blood cells present in the cerebrospinal fluid (CSF). Medical treatment was not required. In four cases $\mathrm{GH}$ treatment was reintroduced at a lower dose with progressive incremental doses, without the reappearance of papilledema.

\section{Discussion}

$\mathrm{GH}$ treatment is a risk factor for developing secondary PTCS although the mechanism is little understood. Two hypotheses have been proposed. The first is that GH could have a physiological antidiuretic effect, causing retention of sodium and water and expansion in blood volume, and reducing CSF resorption by the arachnoid villi. The second hypothesis proposes that GH would cross the blood-brain barrier, resulting in raised cerebral levels of $\mathrm{GH}$ and its mediator, insulin-like growth factor 1 , and finally increasing CSF production $(11,12,13,14)$.

GH was initially obtained from human pituitary gland, and was given at lower doses and frequency, and prescribed in fewer clinical situations. Since 1985, when recombinant human GH became commercially available, more patients were treated with larger doses and more often. Since then, indications for $\mathrm{GH}$ treatment have increased, as well as the potential adverse effects (15).

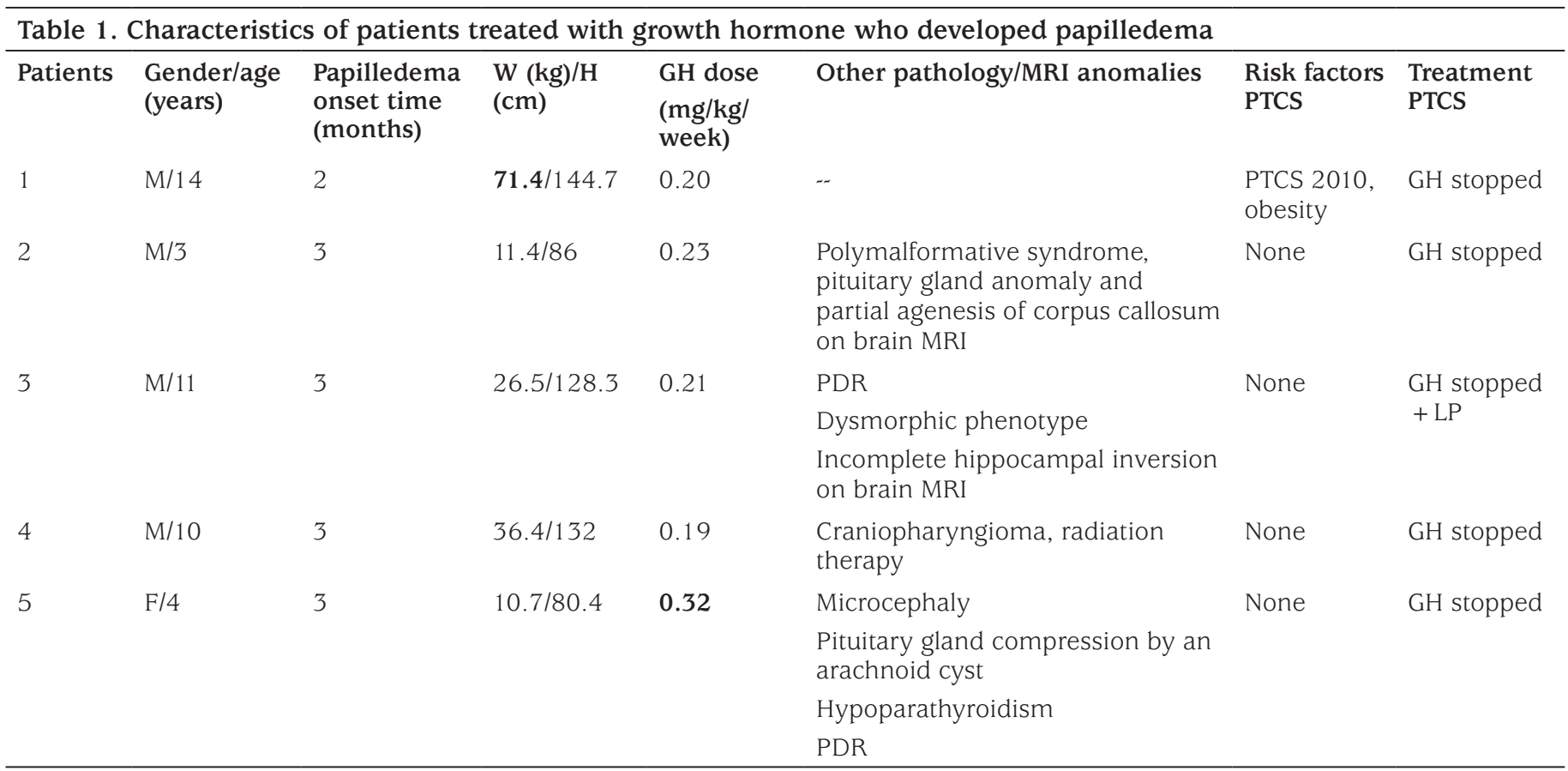

F: female, GH: growth hormone, H: height, LP: lumbar puncture, M: male, MRI: magnetic resonance imaging, PDR: psychomotor development retardation, PTCS: pseudotumor cerebri syndrome, W: weight 


\begin{tabular}{|c|c|c|c|}
\hline & GH deficiency subgroups & $\mathrm{N}^{\circ}$ patients & $\mathrm{N}^{\circ}$ papilledema \\
\hline 1 & Isolated GH deficiency with normal H-P axis on MRI & 164 & 1 \\
\hline 3 & Genetic or chromosome disorders & 18 & 1 \\
\hline
\end{tabular}

GH: growth hormone, H-P: hypothalamic-pituitary, MRI: magnetic resonance imaging, RT: cranial radiotherapy

In our study, there were five patients with papilledema $(1.7 \%)$, a higher incidence compared with the expected incidence in the general paediatric population $(8,9,11,13)$. All of them had $\mathrm{GH}$ deficiency. Other indications for $\mathrm{GH}$ treatment did not appear to cause papilledema in this series, although these results may be biased due the small populations with these other indications.

As all the patients with papilledema were found to have $\mathrm{GH}$ deficiency, we analysed this group, classifying patients into three subgroups (Table 2):

1. Isolated GH deficiency (no other associated hormone deficiencies) with normal hypothalamic-pituitary axis anatomy on MRI.

2. Isolated GH deficiency or associated with other hormone deficiencies with altered hypothalamic-pituitary axis anatomy on MRI and/or past history of cerebral radiotherapy.

3. GH deficiency in patients with genetic or chromosomal diseases.

When considering patients who presented with papilledema, three completed criteria for subgroup 2, presenting with hypothalamic-pituitary axis abnormalities and external radiotherapy treatment in one case for a suprasellar tumour. These three patients in subgroup 2 had an intracranial hypertension, but not technically a PTCS, because the brain MRI was not normal. One other patient was classified as subgroup 3 for a non-specific genetic disease. Only one patient presented with an isolated GH deficiency with normal cerebral MRI, however this patient had had primary PTCS five years earlier. The patient with a suprasellar tumour also had a ventriculoperitoneal shunt, suggesting that the presence of a shunt is not protective against a rise in ICP induced by GH therapy.

For each GH indication, the incidence of this adverse effect can vary. Reeves and Doyle (8), reported higher incidences in patients with renal failure and Turner syndrome. Souza and Collet-Solberg (11), also detected a higher incidence in patients with chronic kidney disease. Darendeliler et al (16) proposed that patients with Turner syndrome, organic $\mathrm{GH}$ deficiency, PWS and chronic renal insufficiency might be more prone to develop papilledema when receiving $\mathrm{GH}$. In our study, patients with renal disease were excluded, as the GH was not prescribed by the Paediatric Endocrinology Department. However, we have conducted a retrospective study of these patients with renal disease on GH treatment during the same time period and have also detected a higher incidence of papilledema, as described in the literature.

The association between the dose of GH and the risk of PTCS is not clearly established. Malozowski et al (15) reported that higher doses and increased frequency of administration since the introduction of recombinant human GH in 1985 may be contributing to the development of PTCS in some patients. However, Reeves and Doyle found no relationship between the GH dose and PTCS development (8). One of our patients received $\mathrm{GH}$ at the usual dose without complications, later on it was withdrawn due to lack of therapeutic effect. Interestingly, papilledema appeared three months after restarting $\mathrm{GH}$ at a higher dose. Patients with PWS and mutations in the SHOX gene, who received higher doses of GH did not present with papilledema, although these subgroups were small in this study. Even though there is no evidence that the $\mathrm{GH}$ dose is directly related with this complication, we recommend starting at lower dose and increasing it progressively, in order to minimize this complication.

Patients with a previous history of PTCS may experience recurrence at rates reported to vary between 6-22\% $(4,17,18,19)$. There is usually a triggering factor, such as weight gain or the introduction of known medications associated with secondary PTCS (20). In our series, the only patient with a previous history of PTCS, presented with papilledema. This patient was obese, which could have been a further risk factor for primary PTCS recurrence, however his weight had remained stable prior to starting GH treatment, at one month and at two months of treatment, when papilledema was diagnosed. For this reason, we believe it is important to identify patients initiating GH therapy with a previous history of PTCS because of the risk of recurrence. Also, consideration should be taken for starting treatment at a lower dose with progressive increases, accompanied by with careful follow-up including fundus examination during the first months of treatment.

Headache is a common symptom in the general paediatric population, and is also relatively frequent in patients on $\mathrm{GH}$ 
therapy, being the third most prevalent side effect described in KIGS (Pfizer International Growth study database) (16). On the other hand, headache is the main manifestation of intracranial hypertension at any age. However, in the paediatric population, headache is less common and $33 \%$ of children with PTCS may be totally asymptomatic $(21,22)$, and diagnosis is only made on the observation of papilledema on fundus examination. It is important to highlight that papilledema is a cause of visual morbidity, including irreversible vision loss, independent of the patient symptoms. In our series, all patients with papilledema were asymptomatic, whereas no patients examined urgently for headache presented with papilledema.

Stopping GH is usually enough to treat this complication. Once papilledema has resolved GH can be reintroduced at a lower dose and progressively increased until the required dose is achieved to prevent recurrence and optimum growth. In the four patients where $\mathrm{GH}$ was reintroduced there were no recurrences of papilledema.

\section{Study Limitations}

The strengths of our study are the prospective design and the number of patients included in it. As children may be asymptomatic, prospective studies are the only way to establish the real incidence of this complication. The main limitation of our study is that patients with kidney diseases were not included and this group of patients has been reported to be at greatest risk of this complication in a different series.

\section{Conclusion}

In this study, we have shown that GH therapy is a risk factor for intracranial hypertension and the at-risk group were patients with GH deficiency and hypothalamic-pituitary axis abnormalities on MRI or genetic or chromosomal diseases. Patients may be totally asymptomatic, so fundus examination should be systematically implemented in this at-risk group, irrespective of the presence or absence of symptoms.

\section{Acknowledgments}

We thank Dr. Susana Noval for her valuable contribution in the analysis and interpretation of data and Dr. Silvia Muñoz for critical review of the manuscript.

\section{Ethics}

Ethics Committee Approval: Ethics approval was obtained from the Ethic Review Committee of the Hospital Universitario Vall d'Hebron (approval number: 383, date: 17.05.2019).
Informed Consent: All subjects (or their parents or guardians) gave their written informed consent.

Peer-review: Externally peer-reviewed.

\section{Authorship Contributions}

Surgical and Medical Practices: Nieves Martín-Begué, Eduard Mogas, Charlotte Wolley Dod, Silvia Alarcón, María Clemente, Ariadna Campos-Martorell, Ana Fábregas, Diego Yeste, Concept/Design: Nieves Martín-Begué, Eduard Mogas, Charlotte Wolley Dod, Silvia Alarcón, María Clemente, Ariadna Campos-Martorell, Ana Fábregas, Diego Yeste, Data Collection or Processing: Nieves MartínBegué, Eduard Mogas, Charlotte Wolley Dod, Silvia Alarcón, María Clemente, Ariadna Campos-Martorell, Ana Fábregas, Diego Yeste, Analysis or Interpretation: Nieves Martín-Begué, Eduard Mogas, Charlotte Wolley Dod, Silvia Alarcón, María Clemente, Ariadna Campos-Martorell, Ana Fábregas, Diego Yeste, Literature Search: Nieves MartínBegué, Eduard Mogas, Charlotte Wolley Dod, Silvia Alarcón, María Clemente, Ariadna Campos-Martorell, Ana Fábregas, Diego Yeste, Writing: Nieves Martín-Begué, Eduard Mogas, Charlotte Wolley Dod, Silvia Alarcón, María Clemente, Ariadna Campos-Martorell, Ana Fábregas, Diego Yeste.

Financial Disclosure: The authors declared that this study received no financial support.

\section{References}

1. Friedman DI, Liu GT, Digre KB. Revised diagnostic criteria for the pseudotumor cerebri syndrome in adults and children. Neurology 2013;81:1159-1165. Epub 2013 Aug 21

2. Rangwala LM, Liu GT. Pediatric Idiopathic Intracranial Hypertension. Surv Ophthalmol 2007;52:597-617

3. Matthews YY, Dean F, Lim MJ, Mclachlan K, Rigby AS, Solanki GA, White CP, Whitehouse WP, Kennedy CR. Pseudotumor cerebri syndrome in childhood: incidence, clinical profile and risk factors in a national prospective population-based cohort study. Arch Dis Child 2017;102:715-721. Epub 2017 Mar 29

4. Ko MW, Liu GT. Pediatric idiopathic intracranial hypertension (Pseudotumor cerebri). Horm Res Paediatr 2010;74:381-389. Epub 2010 Oct 21

5. Scott IU, Siatkowski RM, Eneyni M, Brodsky MC, Lam BL. Idiopathic intracranial hypertension in children and adolescents. Am J Ophthalmol 1997;124:253-255.

6. Digre KB, Bruce BB, McDermott MP, Galetta KM, Balcer LJ, Wall M; NORDIC Idiopathic Intracranial Hypertension Study Group. Quality of life in idiopathic intracranial hypertension at diagnosis: IIH treatment trial results. Neurology 2015;84:2449-2456. Epub 2015 May 20

7. Malozowski S, Tanner A, Wysowski D, Fleming GA. Growth hormone, insulin-like growth factor I, and benign intracranial hypertension. N Engl J Med 1993;329:665-666.

8. Reeves GD, Doyle DA. Growth hormone treatment and pseudotumor cerebri: coincidence or close relationship? J Pediatr Endocrinol Metab 2002;15(Suppl 2):723-730. 
9. Rogers AH, Rogers GL, Bremer DL, McGregor ML. Pseudotumor cerebri in children receiving recombinant human growth hormone. Ophthalmology 1999;106:1186-1189.

10. Mollan SP, Markey KA, Benzimra JD, Jacks A, Matthews TD, Burdon MA, Sinclair AJ. A practical approach to, diagnosis, assessment and management of idiopathic intracranial hypertension. Pract Neurol 2014;14:380-390. Epub 2014 May 8

11. Souza FM, Collet-Solberg PF. Adverse effects of growth hormone replacement therapy in children. Arq Bras Endocrinol Metab 2011;55:559-565

12. Johansson JO, Larson G, Andersson M, Elmgren A, Hynsjö L, Lindahl A, Lundberg PA, Isaksson OG, Lindstedt S, Bengtsson BA. Treatment of growth hormone-deficient adults with recombinant human growth hormone increases the concentration of growth hormone in the cerebrospinal fluid and affects neurotransmitters. Neuroendocrinology 1995;61:57-66.

13. Darendeliler F. Safety of Growth Hormone Treatment. J Clin Res Pediatr Endocrinol 2009;1(Suppl 1):36-43.

14. Saenger P. Metabolic consequences of growth hormone treatment in paediatric practice. Horm Res 2000;53(Suppl 19:60-69.

15. Malozowski S, Tanner LA, Wysowski DK, Fleming GA, Stadel BV. Benign intracranial hypertension in children with growth hormone deficiency treated with growth hormone. J Pediatr 1995;126:996-999.
16. Darendeliler F, Karagiannis G, Wilton P. Headache, idiopathic intracranial hypertension and slipped capital femoral epiphysis during growth hormone treatment: a safety update from the KIGS database. Horm Res 2007;68(Suppl 5):41-47. Epub 2007 Dec 10

17. Soiberman U, Stolovitch C, Balcer LJ, Regenbogen M, Constantini $\mathrm{S}$, Kesler A. Idiopathic intracranial hypertension in children. Visual outcome and risk of recurrence. Childs Nerv Syst 2011;27:1913-1918. Epub 2011 May 3

18. Tibussek D, Schneider DT, Vandemeulebroecke N, Turowski B, MessingJuenger M, Willems PH, Mayatepek E, Distelmaier F. Clinical spectrum of the pseudotumor cerebri complex in children. Childs Nerv Syst 2010;26:313-321. Epub 2009 Nov 10

19. Aylward SC, Way AL. Pediatric Intracranial hypertension: a current review. Curr Pain Headache Rep 2018;22:14.

20. Ko MW, Chang SC, Ridha MA, Ney JJ, Ali TF, Friedman DI, Mejico LJ, Volpe NJ, Galetta SL, Balcer LJ, Liu GT. Weight gain and recurrence in idiopathic intracrnial hypertension: a case-control study. Neurology 2011;76:1564-1567.

21. Bassan H, Berkner L, Stolovitch C, Kesler A. Asymptomatic idiopathic intracranial hypertension in children. Acta Neurol Scand 2008;118:251255. Epub 2008 Mar 12

22. Aylward SC, Reem RE. Pediatric Intracranial Hypertension. Pediatr Rev 2018;39:121-129. 